\title{
Gregório Ronca e Ermanno Stradelli: oficial da marinha e antropólogo na Amazônia
}

\author{
Gregório Ronca and Ermanno Stradelli: \\ navy officer and anthropologist in the Amazon
}

\author{
Vittorio Cappelli* \\ (Tradução de Núncia Santoro de Constantino)
}

\begin{abstract}
Resumo: $\mathrm{O}$ texto propõe-se descrever, comentar e comparar as duas experiências de viajantes italianos na Amazônia entre os séculos XIX e XX. Trata-se das explorações e das atividades de Ermanno Stradelli, etnólogo que viveu e trabalhou na Amazônia de 1879 a 1926, e da missão exploradora de Gregório Ronca, oficial da Marinha italiana que, em 1904, viajou para as Antilhas, às Guianas, à Amazônia, subindo o rio Amazonas de Belém para Manaus e Iquitos, para avaliar os interesses comerciais da Itália, e para encontrar as comunidades italianas naquelas cidades.
\end{abstract}

Palavras-chave: Viajantes italianos. Amazônia. Borracha. Imigração Italiana.

Abstract: The intervention is intended to describe, comment and compare the experiences of two Italian travellers in Amazonas between the Eighteenth and the Nineteenth Centuries. The explorations and acts of Ermanno Stradelli, ethnologist who was been living and working in Amazonas since 1879 to 1926, and the explorative mission of Gregorio Ronca, Italian Navy's officer, who in 1904 travelled from the Antilles to the Guyanas and Amazonas, going up the Amazon from Belém to Manaus and Iquitos, in order to enquiry on commercial Italian interests and to meet Italian communities in those towns.

Keywords: Italian travellers. Amazonas. Rubber. Italian immigration.

* Laureado em Filosofia na Università di Milano (1971). É professor de História Contemporânea na Università della Calábria. Desenvolveu pesquisas sobre a história social da Calábria, com destaque ao associativismo, conflitos sociais e emigração transoceânica na América Latina. 
Num dia de primavera, em 1904, no porto de Nápoles, Gregorio Ronca, capitão de fragata da Marinha Militar Italiana, recebia a visita de sua majestade o Rei Vittorio Emanuele III, a bordo do Dogali, um navio oceânico de guerra de 2.200 toneladas, 76 metros de comprimento, dotado de canhões, metralhadoras e lança-torpedos. O soberano queria cumprimentar o capitão Ronca, que estava prestes a partir, não para uma ação de guerra, mas para uma missão de paz, a ser conduzida nas Antilhas, Guianas e sobretudo na Amazônia, com o objetivo de verificar a possibilidade de desenvolver naquelas regiões as relações comerciais italianas, tratando também da emigração.

Gregorio Ronca, à época com 45 anos, robusto e entusiasmado, possuía uma notável experiência de pesquisa científica no campo da balística e também a experiência decorrente de uma longa viagem de circunavegação. Quando era muito jovem, na corveta a vapor Caracciolo, comandada pelo almirante Carlo de Amezaga, partiu de Nápoles para a América do Sul, ficando por dois meses em Montevidéu, (onde a tripulação entrou em contato com a grande colônia italiana) e depois no porto peruano de Callao, durante um ano inteiro, no curso do qual a corveta sondava a costa do Pacífico até o Panamá. Abandonada a América, o navio dirigiu-se ao Taiti, depois a Singapura, Sumatra e Ceilão; dali às ilhas Seychelles e depois a Aden. Atravessado o Mar Vermelho e Suez, alcançou Veneza em 21 de setembro de 1884, depois de quase três anos de viagem.

Iniciado na navegação transoceânica nesta longa viagem, Gregorio Ronca, depois de vinte anos de carreira, recebera o prestigiado encargo, mas também que também exigia muito esforço. Deveria subir o inteiro curso do rio Amazonas, até as remotas cidades de Iquitos e Santa fé, em território peruano, ao término de um tour de exploração nas principais ilhas do Caribe e nas Guianas. A navegação fluvial na Amazônia durou 74 dias, no fim dos quais foram percorridas 4570 milhas, entre ida e volta, cerca de 8.464 quilômetros.

A tarefa confiada a Ronca era individualizar os portos, as regiões e os países que "alcançassem ser úteis à prosperidade nacional", considerando "o comércio e aquela maravilhosa atividade imigratória da nossa gente; mercê da qual a nova Itália pode espalhar pelo mundo 4 milhões dos seus filhos, sem experimentar danos, mas oferecendo benefícios". Ronca era convicto de dever sobretudo "estudar os interesses da emigração, porque no maior número de casos acontece que a expansão do nosso comércio se manifesta onde essa está estabelecida". 
Deste ponto de vista, a imensa bacia amazônica era o potente imã de toda a viagem de exploração, porque Ronca sabia perfeitamente que "sobre isso logo estará a atenção de todo o mundo civilizado". Em 1904, de fato, estava no auge do triunfo o ciclo econômico da borracha, que prometia posteriores desenvolvimentos, garantidos pela expansão da indústria ciclística e automobilística, fosse europeia ou norte-americana. E a Itália arriscava ficar de fora desta grande oportunidade, visto que recém havia terminado, e bastante mal, a experiência da línha direta de navegação entre Gênova e Manaus, empreendida pela Compagnia di Navigazione Ligure-Brasiliana, dirigida por Gustavo Gavotti.

Parece evidente que Ronca havia sido encarregado pelo governo italiano de tentar novos percursos, para evitar que a Itália perdesse o papel adquirido na Amazônia da borracha, ainda que fosse um papel marginal. Considere-se que, diante de uma transbordante hegemonia britânica, a Alemanha e a Itália eram os únicos países europeus a ter uma certa presença nos tráficos comerciais da bacia amazônica. É o mesmo Ronca a informar que, em 1901, no porto de Belém, haviam atracado em entrada 229 vapores britânicos, 23 alemães e 19 italianos. E no porto fluvial de Manaus as proporções se repetiam: os vapores em entrada eram 101 britânicos, 12 alemães e 9 italianos.

A exploração de Ronca tem, então, objetivos práticos e prosaicos. Mas a viagem coloca em jogo emoções profundas e deve enfrentar o desafio dos riscos e dificuldades de grande monta. Todavia, a atitude do capitão no comando da fragata mostra ser amparada por uma base cultural não muito comum em oficiais da marinha. No início da viagem fluvial, comentando a paisagem do baixo curso do rio Amazonas, observa: "A floresta é sempre bela, há contínuas e numerosas variações, que têm sempre nossa atenção e suscitam entusiasmo; não compartilho da opinião de Alexandre Humboldt, quando provava um sentimento de tristeza diante do espetáculo desta natureza assim viva, onde só não figura o homem. "Pelo contrário, aquela magnitude natural sempre me inspirou um senso de admiração misturado a um sentimento de orgulho pela segurança de que, num futuro próximo, o homem submeterá aquela natureza rebelde às suas necessidades".

No orgulho de Ronca, defronte à tristeza do grande naturalista alemão Von Humboldt, fica evidente a formação cultural positivista do comandante, que não se deixa de todo capturar pela potência da natureza: "ao pôr-do-sol, estranhas sombras penetram entre as árvores e se adensam numa obscuridade de mistério que parece esconder a infância de uma nova civilização, próxima a florescer 
sobre esse imenso campo virgem reservado às atividades das próximas gerações".

Os "magníficos e progressistas destinos" acenados com doloroso sarcasmo no memorável ataque leopardiano (Giacomo Leopardi, La ginestra, v. 51) são, sem dúvida e com convicção, palavras resultantes do sólido otimismo de Ronca, que identifica tais destinos na civilização ocidental, principalmente quando esta chegar à Amazônia. Todavia, a confiança do comandante Ronca é tudo menos cega; é acompanhada também por uma atenção pouco comum aos custos sociais e humanos da civilização. É acompanhada por uma séria reflexão sobre a vida e destinos das populações indígenas. Leia-se esta passagem da sua crônica de viagem amazônica: "os índios selvagens [...] quando conseguem ter uma carabina, coisa que não é difícil, tornam-se [...] inimigos bastante temíveis para os brancos. E assim se explicam certas hecatombes de seringueiros; mas para ser justo, é preciso também dizer que aqueles massacres são uma das consequências das condições gerais de um ambiente onde a lei é só a força. Na verdade, não é raro que, ao invés de tentar educar os índios, os homens ditos civilizados organizam entradas na floresta para assaltar as tribos, roubar o pouco que têm, capturar as crianças, matar velhos e adultos que não conseguiriam domesticar. Todos sabem dizer quanto se paga por um rapaz ou por uma menina caçados deste modo. Entretanto, se os índios matam combatendo para defender suas vidas, crianças e bens, ou matam à traição por represália, a culpa é da gente que se vangloria de ser mais civilizada do que os índios. De resto são os comerciantes que lhes armam, trocando fuzis e munição por borracha e por outros produtos da floresta que também são colhidos pelos selvagens".

A denúncia é verdadeiramente forte e inequívoca. Está acompanhada também por uma lúcida e precavida preocupação relativa à conservação do equilíbrio natural na bacia amazônica: "precisaria que a exploração e a derrubada da floresta, assim tão economicamente importante, [...] fosse regulada por sábias leis [...] para a conservação daquela parte da floresta que a ciência tem como necessária à higiene e manutenção das convenientes condições climatológicas. Mas prossigamos na viagem de retorno pelo "mar doce" amazônico, detendo-nos nos objetivos e nas principais preocupações do empreendimento. Já em Belém, porta de ingresso à navegação fluvial, Ronca registra a febril novidade da época. A cidade, que cento e vinte anos antes possuía apenas 12.000 habitantes, já contava com 125.000 e se apresentava com o seus "longos cais de ferro e madeira" e "as chaminés de algumas oficinas mecânicas". "Atrás 
dos molhes se estende uma praça arborizada e uma larga rua na qual se encontram numerosas casas de comércio". Mais adiante se avistam "largas ruas em construção, espaçosas avenidas bem arborizadas, graciosos jardins, largas e belas praças" [...] "uma velha catedral, o teatro, o palácio do governo" [...] "quatro bibliotecas, várias casas bancárias, um museu com jardim botânico" [...] "muitas escolas para o ensino elementar e secundário, para artes e ofícios, fábricas de sabão, cera, biscoitos, licores, velas" [...] "um bom sistema de iluminação elétrica e muitas casas em construção (parece que nos últimos anos foram feitas 800 por ano)".

Ronca não escreve mas, neste cenário, decisivo é o papel dos italianos, trabalhando às centenas como artesãos e comerciantes (sapateiros, alfaiates, ferreiros, mestres de obra, operários por jornada, vendedores de fruta, etc.), que desempenham um papel importante no desenvolvimento do processo de crescimento e industrialização da cidade. Também nas camadas médio-altas da sociedade urbana registra-se a presença significativa dos italianos. Eles se encontram na da construção do Teatro da Paz (1878), tendo como modelo o Teatro Scala de Milão e decorado pelos artistas da Accademia di San Luca, de Roma, como Domenico De Angelis e Giovanni Capranesi; encontram-se nas construções ecléticas do engenheiro calabrês Filinto Santoro (19031913), ou no âmbito da música, como é o caso do vicentino Ettore Bosio.

A única presença italiana verbalizada por Ronca é aquela do agente consular Malagutti, que lhe põe à disposição um embarcação para localizar os canais mais adequados a serem utilizados pelo navio para entrar no Rio Amazonas. A viagem de Ronca deve ter pronto início, para logo alcançar os principais pontos comerciais do baixo curso do Amazonas, isto é, Santarém e Óbidos. E ali surge a ocasião para uma agradável constatação feita pelo comandante, que poderá indicar possíveis desembarcadouros para novas correntes migratórias italianas.

Em Santarém, uma cidadezinha com poucos mil habitantes, tem "um bom cais de madeira e ferro no qual podem encostar navios". Há telégrafo e um escritório alfandegário; o rio tem ali 22 quilômetros de largura. Ronca, para quem "era sabido que ali se encontravam muitos italianos", acolhe "a bordo quase toda a colônia". Demonstram entusiasmo e são quase todos originários de San Costantino di Rivello, um povoado da Lucânia que se debruça das montanhas sobre o golfo de Policastro. O comandante pode assim observar "um exemplo daquele fenômeno pelo qual, impulsionados pelo exemplo, pelas promessas e encorajamentos dos seus companheiros, as pessoas de um mesmo município que se 
decidem a emigrar vão onde o acaso empurra o primeiro deles". Esta cadeia migratória lucana já havia trazido um caldeireiro, anos antes. Esses imigrantes se dedicam com notável sucesso ao comércio de toda a espécie de mercadorias, quase sempre procedentes da França e não da Itália, com a qual as comunicações são difíceis e custosas, por causa do transbordo em Lisboa que se tornou necessário depois do fechamento da linha de navegação direta entre Gênova e Manaus.

Mais adiante, no Passo de Óbidos, onde o grande rio faz-se estreito e profundíssimo, na cidadezinha homônima, Ronca encontra outra comunidade italiana, ainda mais numerosa e rica, constituída quase por inteiro de parentes daquela de Santarém, provenientes portanto de San Costantino di Rivello. Ronca registra a atividade de "14 casas comerciais com um capital de cerca de dois milhões de liras, e narra com agrado: "recebi logo a visita entusiástica da colônia e notei com satisfação que veio acompanhada de autoridades da cidade e dos notáveis, porque todos os seus membros são tidos em grande conta e muito estimados. Mas continuemos a viagem, subindo o "mar doce" amazônico, detendo-nos nos objetivos e nas principais ocupações da grande empresa.

A escala sucessiva é aquela de Manaus. Depois de haver entrado no Rio Negro, do Dogali começam a ser avistados os grandes vapores ancorados diante da cidade, " toda risonha pelas cores alegres das suas casas novas, sobre as quais dominam a agulha da catedral e a cúpula do teatro". É o dia de Natal e, do cais flutuante do porto de Manaus, afastam-se dois vaporzinhos em direção ao Dogali, sobre os quais drapejam numerosas bandeiras italianas. É uma representação exultante da colônia italiana, acolhida no Dogali ao som da marcha real. Alguns dias depois serão os imigrantes a acolher a tripulação do navio, em uma festa patriótica organizada em grande pavilhão construído no meio da floresta.

O capitão Ronca se fixa com atenção na cidade e nos italianos que ali trabalham. Manaus lhe parece atraente, toda iluminada por luz elétrica e percorrida por bondes elétricos. "As casas e os edifícios da cidade tem geralmente um belo aspecto", dispostos "em ruas largas e retas, cortadas em ângulos retos. [...] Nota-se a catedral, o teatro, o palácio da justiça, o depósito de água potável, o mercado; à minha passagem pela cidade estavam em construção o palácio do governador e o do parlamento, a penitenciária, etc. Ronca não diz, ou talvez não saiba, mas em muitos desses edifícios- como acontecia também em Belém - estava a mão-de-obra dos italianos: a catedral de São Sebastião, construída por missionários franciscanos e decorada com pinturas de Domenico 
De Angelis; o Teatro Amazonas, frequentado pelas companhias líricas italianas e decorado pelo mesmo De Angelis, que coloca também uma escultura monumental na praça defronte; o palácio do governo, que ficou por terminar, projetado por Filinto Santoro, etc.

$\mathrm{O}$ nosso comandante prefere deter-se nos muitos trabalhadores italianos imigrantes na cidade: "A nossa colônia (com cerca de 2.000 membros) é bastante numerosa em relação à escassa população [os habitantes de Manaus são 45.000], mas conta pouco ou nada, porque é composta em geral por gente pobre, sem ligação e união. Assim que esses bons trabalhadores são simplesmente explorados sem formar aquele grupo, que seria tanto útil para eles como para os interesses da Itália. [...] Muitos desses [...] esqueceram até mesmo a sua língua [...] e a gente do país os chama por um nome genérico que quer dizer carregador. Há um grupo de operários que trabalha bem e também ganha bem, e 60 ou 70 pessoas, entre empregados e comerciantes que estão em razoável posição social e poderiam reunir em torno a colônia, como a representaram nas festas oferecidas à tripulação do Dogali”.

Outras fontes coevas e sucessivas reforçam a representação de uma comunidade presente de forma significativa nas pequenas empresas, no comércio, grande ou pequeno, mas não no comércio da borracha. E se muitos pretendem voltar à Itália apenas seja possível, outros se radicarão estavelmente, mesmo depois do declínio da borracha. A proveniência dos imigrantes italianos é ali também predominantemente lucana e, na comunidade, emerge uma cadeia migratória vinda de Castelluccio Inferiore.

Mas a viagem de Ronca tem suas metas e urgências. Logo o Dogali deixa Manaus e inicia a subida do Amazonas e Solimões, na direção de Iquitos, no território peruano. Quando alcança o destino, apesar de saber que está numa extrema fronteira, o comandante encontra uma pequena colônia de italianos: "soube que ali eram uns cinquenta, mas que ao longo do rio havia outros, sendo que alguns em boas condições financeiras. Também aqueles de Iquitos e geralmente faziam bons negócios: os mais afortunados tinham lojas de mercadorias em geral, um comandava um restaurante (o melhor do lugar), outros eram empregados nos mesmos negócios dos italianos ou trabalhavam como operários. [...] Toda a colônia gozava de ótima reputação e era muito estimada. Um único mal, ainda que grande, a rodeava: as discórdias internas produzidas por razões fúteis ou, é doloroso dizer, pelo regionalismo". Malgrado isso, existe há alguns anos uma sociedade italiana de beneficência. 
Depois de uma semana, o Dogali, subindo o Marañón, vai na direção de Santa Fe, última etapa da viagem, "a 2.285 milhas pelo mar, onde jamais havia chegado outro navio". Em 30 de janeiro de 1905 inicia o retorno, a descida do rio, que terminará em 23 de fevereiro, depois de 74 dias de navegação fluvial.

As conclusões de Ronca acerca do possível desenvolvimento da imigração italiana na Amazônia são inequívocas: deve ser evitada a colheita da borracha, que apresenta um risco de tornar-se escravidão, praticada por seringueiros; o percurso a seguir deve ser aquele que fizeram os imigrantes lucanos "que se estabeleceram em Óbidos e Santarém", transformando-se em comerciantes "graças aos bons lucros e à sua habitual virtude de sobriedade e parcimônia”. Em geral, na Amazônia, "estando tudo por fazer", é muito procurado o trabalho de operários. "Por isso os pedreiros, fabricantes de tijolos, oleiros, serventes de pedreiro, cinzeladores, funileiros, latoeiros, faqueiros, amoladores, pintores, calafates, embaladores, caixeiros e cordoeiros encontram emprego fácil, imediato e bem remunerado; como também acontece para os cozinheiros, empregados domésticos, empregados em cafeterias, confeiteiros, empregados em restaurantes, carregadores, barbeiros; e finalmente a navegação fluvial faz muito procurados os mecânicos e maquinistas".

Dito isso, segundo Ronca, para que se abram possibilidades para a imigração italiana, é necessário evitar os erros da Compagnia di Navigazione Ligure-Brasiliana e, sobretudo, superar as divisões regionalistas e bairristas entre imigrantes italianos.

\section{$* * *$}

Na crônica de viagem amazônica do comandante Ronca há um detalhe para não deixar desapercebido. O nosso oficial encontra em Manaus o conde Ermanno Stradelli, que lhe mostra o seu mapa geográfico do Estado do Amazonas, compilado alguns anos antes, e também um "álbum de mapas hidrográficos do Pará a Tabatinga". O encontro com Stradelli deve ter sido de muita importância. As mesmas reflexões de Ronca sobre violências perpetradas contra os índios, das quais já havíamos falado, são provavelmente devedoras desta interlocução com o grande antropólogo italiano, chegado na Amazônia em 1879, que a cultura brasileira do século XX generosamente adotou, enquanto a cultura antropológica italiana resiste em reconhecer como um ilustre pioneiro. 
É fácil imaginar que Stradelli tenha discutido com Ronca sobre o possível papel econômico da Itália na Amazônia da borracha, mas certamente não deve ter-lhe transmitido otimismo. Sete anos antes, de fato, o antropólogo retornara à Itália para tentar convencer a indústria Pirelli a empenhar-se diretamente na extração da borracha. Era em 1894, o mesmo ano em que o empreendedor genovês Gustavo Gavotti inaugurava a linha de navegação Gênova-Manaus, que parecia prometer novas fortunas ligadas ao tráfico da borracha, recebendo no meio-tempo em seus navios emigrantes esperançosos e corajosos, junto a músicos e cantores das companhias líricas que se dirigiam aos teatros de Belém e Manaus. A tentativa de Stradelli, entretanto, não alcançou sucesso, pois Giovanni Battista Pirelli não o escutou. E Stradelli nunca mais voltaria à Itália. Dedicou o resto de sua vida à exploração do território, ao estudo e à defesa das culturas indígenas, colocadas em perigo desde os tempos do triunfo da borracha.

Era ainda em 1889 - a pouco mais de vinte anos da abertura da Amazônia à navegação internacional - quando Stradelli assim escrevia no Bollettino della Società Geografica Italiana:

Aqui estamos em pleno momento da extração da goma elástica; não se fala de outra coisa, não se pensa em outra coisa. A goma elástica é o recurso e a ruína do Rio Negro. Aquilo que a perseguição e a exigência dos governadores [e] das autoridades [...] não haviam podido fazer, a goma elástica fez... É à ela e não a outro que se deve atribuir o estado atual do Alto e do Baixo Rio Negro, a decadência rápida e irremediável das suas populações, mesmo que florescentes e prósperas, o abandono de cada cultura... Com frequência o atraso de um vapor traz carestia.

Naturalmente Stradelli não tem grande consideração pelos missionários que "concorrem involuntariamente à mais rápida corrupção dos indígenas" que, quando se fixaram nas vilas das missões religiosas, " deram o primeiro passo do próprio aviltamento", subscrevendo o primeiro artigo do seu não distante ato de morte.

Mas a questão principal é aquela da borracha. Stradelli - que não é um crítico radical da modernidade mas um homem do seu tempo, dominado por um horizonte cultural positivista, seja pelo abundantemente diluído gosto romântico pessoal - não se contrapõe à extração do latex a escopo industrial, tanto é que decide tentar a única tentativa de envolver a indústria italiana, contatando, como já foi dito, 
Giovanni Battista Pirelli, sem resultado algum, na vã esperança de convencê-lo a constituir uma associação ítalo-brasileira para a extração da goma.

No curso das suas investigações, ele emprega sistematicamente a sua máquina fotográfica e o microscópio, que impressionam muito os indígenas, a ponto de fazê-lo parecer dotado de poderes mágicos. Em Manaus, no ano de 1884, ele coloca a primeira pedra para a construção do suntuoso Teatro Amazonas, por conta de uma firma italiana que havia vencido a primeira concorrência para a construção daquela obra ambiciosa e algo insensata. E, na mesma Manaus, ele mesmo exerce a advocacia e cargos públicos, de 1893 até 1923, quando a lepra lhe é diagnosticada.

Portanto, partilha o processo de civilização no ato, mas se recusa drasticamente a aceitar as implicações violentas e destrutivas diante das culturas indígenas, seja no que se relaciona aos leigos interesses econômicos dos seringueiros e dos coronéis amazônicos, seja relacionado àquele religioso das missões cristãs. Nesta perspectiva, propriamente a respeito das culturas indígenas, percebeu e apreendeu, através da participação direta e da admiração, como se fundamente a transcrição do culto indígena de Yuruparí, que publicou pela primeira vez em 1890 no Bollettino della Società Geografica Italiana. Na narrativa de Stradelli, que assume forma e tons românticos, Yuruparí deixa de ser a figura satânica pintada pelos missionários, para assumir as vestes de um antigo herói, legislador e mestre, celebrado em festas e rituais coletivos, nos quais se revive e se transmite um mito patriarcal de fundação que dá lugar à ordem sexual e social.

Stradelli, naturalmente, desconfiava dos militares, comerciantes e evangelizadores, que nada de bom prometiam a propósito de salvaguardar as populações indígenas. Todavia, temos boas razões para imaginar que o encontro em Manaus entre o oficial Ronca e o antropólogo Stradelli , por alguns momentos, avizinha dois homens bastante diversos por formação e por vocação, mas que têm em comum o sonho de conciliar "missão civilizadora" com respeito pelo"'outro".

Ronca cultivou e formulou este sonho no curso de uma expedição que durou dois meses e meio, durante os quais idealizou uma renovada participação nesta civilização, solicitando e indicando uma correta direção à imigração italiana, para que fosse colhida a oportunidade oferecida pelo ciclo da borracha. Não teve depois tempo para registrar a falência desta perspectiva, porque morreu poucos anos depois. Stradelli, que chegara à Amazônia há um quarto de século e lá ficou por mais 
de vinte anos, até a morte em 1926, ao contrário, constatou dolorosamente toda a carga de violência daquele ciclo econômico, fixado sobre o trabalho forçado dos indígenas e dos migrantes do sertão, até o rápido e catastrófico declínio da borracha amazônica, determinado pelo sucesso do cultivo da borracha pelos britânicos no sudeste asiático.

\section{Referências}

CAPPELLI,Vittorio. La presenza italiana in Amazzonia e nel nord-est del Brasile tra Otto e Novecento. In: CAPPELLI, V.; Hecker, A. (a cura di). Italiani in Brasile. Rotte migratorie e percorsi culturali. Soveria Mannelli: Rubbettino, 2010.

CAPPELLI,Vittorio. Architetti e costruttori italiani nelle città brasiliane (e altrove) tra XIX e XX secolo. In: RAMOS, A. Freire; MATOS, M. I. Santos de; Patriota, R. (a cura di). Olhares sobre a história. Culturas, sensibilidades, sociabilidades. São Paulo: Hucitec, 2010.

CASCUDO, Luis da Camara. Em memoria de Stradelli (1852-1926). Manaus: Livraria Classica, 1936.

DE MAIO, Mimma. Il navigatore-scienziato Gregorio Ronca, un irpino da non dimenticare. Ivi: Accademia Solofra, 1986.

DERENJI, Jussara da Silveira. Arquitetura nortista. A presença italiana no início do século XX. Manaus: SEC, 1998.

DERENJI, Jussara da Silveira. Óbidos. Belém, 1997. (Caderno de Arquitetura, 1).

EMMI, Marilia Ferreira. Italianos na Amazônia. Pioneirismo econômico e identidade (1870-1950). Belém: Edufpa, 2008.

ISENBURG, Teresa. Viaggiatori naturalisti italiani in Brasile nell'Ottocento. Milano: Franco Angeli, 1989.

MANERA, Danilo. Yuruparí: i flauti dell'anaconda celeste. Milano: Feltrinelli, 1999.

MASSA, Gaetano. L'Amazzonia di Ermanno Stradelli. In: Accademia Nazionale delle Scienze detta dei XL, v. XVII, n. 126, 1993.

MESQUITA, Otoni. Manaus. História e arquitetura (1852-1910). Manaus: Valer, 2006.

RONCA, Gregorio. Dalle Antille alle Gujane e all'Amazzonia. In: Rivista Marittima, Roma, 1906; e Annali della Società Geografica, Roma, 1908.

SOUZA, Marcio. História da Amazônia Manaus: Valer, 2009.

STRADELLI, Ermanno. Dal Cucuhy a Manaos. Bollettino della Società Geografica Italiana, 1889.

STRADELLI, Ermanno. La leggenda del Yuruparí e outras lendas amazonicas. São Paulo: Instituto Cultural Italo-Brasiliano, 1964.

WEINSTEIN, Barbara. A borracha na Amazônia: expansão e decadencia, 1850-1920.

São Paulo: Hucitec, 1993. 


\section{Sites:}

$<$ http://bibliotecadigital.fgv.br/dspace/bitstream/handle/10438/7214/Ed2_Traducao com_T.pdf? sequence=1>. (BERNARDINI, Aurora Fornoni. Tradução, com T de Tragedia, Revista Getulio, marzo 2007).

$<$ http://www.instoria.it/home/conte_ermanno_stradelli.htm>. (GUGLIOTTA, Alexandre Carlos. Conte Ermanno Stradelli. Un visionario italiano in Amazzonia. In: In Storia).

Solicitado em 17/09/2012

Aprovado em 18/10/2012 